\title{
No man is an Island: spatial clustering and access to primary care as possible targets for the development of new community mental health approaches.
}

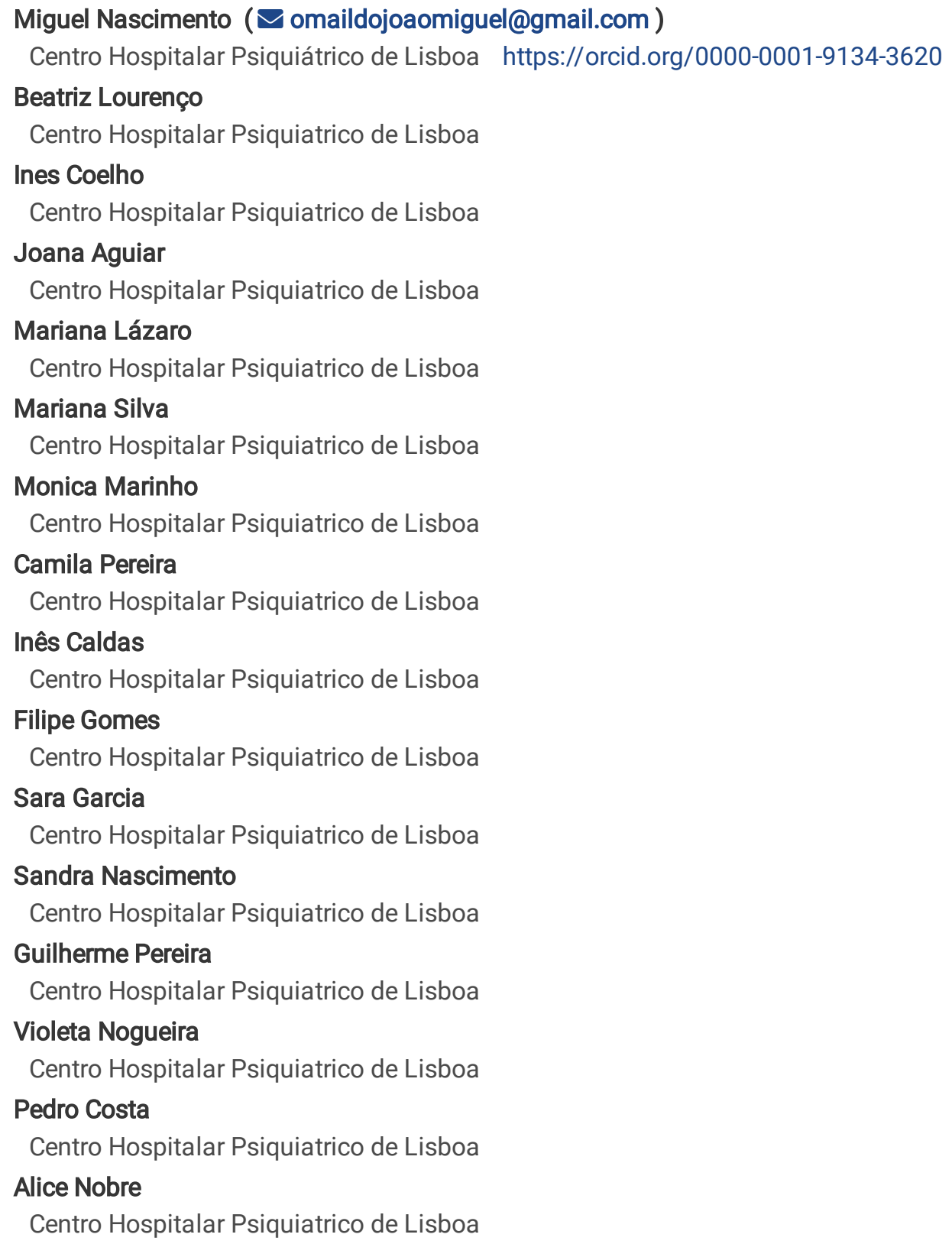

Research article

Keywords: Join count statistics, Clusters, Primary care, Community psychiatry, Access to healthcare

Posted Date: October 1st, 2019

DOI: https://doi.org/10.21203/rs.2.15357/v1 
License: @ (i) This work is licensed under a Creative Commons Attribution 4.0 International License. Read Full License

Version of Record: A version of this preprint was published at BMC Health Services Research on April 22nd, 2020. See the published version at https://doi.org/10.1186/s12913-020-05190-w. 


\section{Abstract}

Purpose: to understand if patients seen at Centro Hospitalar Psiquiátrico de Lisboa (CHPL) live in geographical clusters or randomly throughout the city, as well as determine their access to the psychiatric hospital and primary care facilities (PCF).

Methods: spatial autocorrelation statistics regarding all patients observed at CHPL in 2017, at the census subsection level, considering a queen criterion of contiguity, regarding not only their overall number but also main diagnosis, and admission to the psychiatric ward - voluntary or compulsory. Distance to the hospital and to the closest PCF was measured (for each patient and the variables cited above), and the mean values were compared. Finally, the total number of patients around each PCF was counted, considering specified radius sizes of 656 and $1000 \mathrm{~m}$.

Results: All 5161 patients (509 psychiatric admissions) were geolocated, and statistical significance regarding patient clustering was found for the total number ( $\mathrm{p}-0.0001)$ and specific group of disorders, namely Schizophrenia and related disorders ( $\mathrm{p}-0.007)$ and depressive disorders ( $\mathrm{p}-0.0002)$. Patients who were admitted in a psychiatric ward live farther away from the hospital ( $\mathrm{p}-0.002)$, with the compulsory admissions (versus voluntary ones) living even farther ( $p-0.004)$. Furthermore, defining a radius of $1000 \mathrm{~m}$ for each PCF allowed the identification of two PCF with more than 1000 patients, and two others with more than 800 .

Conclusions: as patients seem to live in geographical clusters (and considering PCFs with the highest number of them), possible locations for the development of programs regarding mental health treatment and prevention can now be identified.

\section{Background}

\section{Social determinants in Mental Health}

Technical literature highlights the importance of various social, economic, and physical environments in which people live, operating at different stages of life and shaping mental health and mental disorders. Social inequalities [1], ethnic density [2] and accessibility to mental health care [3] are some of the social determinants that have been studied during the last years. Physical distance has long been identified as a potential barrier to mental health services, particularly in rural areas [4]. Also, previous studies in other urban cities have demonstrated that, in certain areas, patients appear to reside non-randomly [5] and there are, although sometimes weak, correlations with various ecological factors, such as social organization / safety [6], increased urbanicity [7-9], or increased need of social support [10-15].

\section{Spatial Autocorrelation Statistics serving Community Psychiatry}

The development of mathematical and statistical models applied to spatial coordinates enables the assessment of various social, economic and ecological factors that may operate in the balance between mental health and mental disorders. Characterization and localization of the patient's residence allows not only to identify clusters, but also to cross-link them with the existing primary and secondary care network, in order to understand their relationship with accessibility to care. $[5,16]$

Primary Care Facilities and Community Psychiatry in central and eastern Lisbon

The Portuguese National Health Service (Serviço Nacional de Saúde - SNS), is a complex and constantly evolving system of care. It provides care for all stages of life, not only regarding illness treatment but also in health promotion and primary prevention. It is organized as a network for a better use of resources.

Primary Care Facilities (PCF) are distributed throughout the country at the community level and constitute the first point of contact with the SNS. The PCF are SNS's fundamental pillar, where general and public health physicians, nurses, social workers, psychologists and nutritionists provide care to the population. These teams develop interventions regarding health promotion, early disease detection, initiating appropriate treatments or referring to other specialties if necessary. In the case of mental illness, general practitioners are prepared to treat milder forms of common mental disorders, or when necessary, to ask for consultation or referring to Psychiatry. Psychiatric care provides a more specialised care, taking advantage of different services aiming for secondary, tertiary and quaternary prevention [2]. 
Mental health care in Portugal has been reorganized since the $60 \mathrm{~s}$, following international guidelines in an effort to integrate psychiatric care in general hospitals. Although a long way has already been travelled, there are still some psychiatric hospitals operating in Portugal, namely Centro Hospital Psiquiátrico de Lisboa (CHPL) in Lisbon.

According to the 2011 census, CHPL is responsible for providing direct care to the people living in the central area of Lisbon, with a total of 261350 citizens distributed in a $32.94 \mathrm{~km}^{2}$ fully urban area with a population density of 7934 inhabitants $/ \mathrm{km}^{2}$. It is a predominant urban environment, with heterogenous social and cultural characteristics [17].

In Lisbon, CHPL provides specialized and integrated psychiatric care, framed as an assertive program, using in- and outpatient care, day hospital, occupational therapy, in-home healthcare visits and literacy groups. It articulates with the 15 PCFs operating in this area, based mainly on a referral model, but also on a collaborative approach.

There is a need to establish a closer relationship with the PCF in order to achieve an inspired public health approach that favors a more comprehensive perspective. The ambition to develop and further structure CHPL's community intervention in Lisbon is lined up with the 2020's National Mental Health Program [18, 19], which stresses out the need to improve mental health and psychiatric care in the PCF, as well as the development of literacy programs.

To the authors' knowledge, there are no published papers regarding Lisbon's reality, focusing on the individual characteristics and localization of the patients that evaluate the environment around them and how it can affect mental illness. This study aims to answer the following questions:

1. Do patients live randomly around the city?

2. Do patients with more severe diagnosis have better access to the healthcare facilities?

3. Are there PCFs with higher prevalence of psychiatric patients?

The authors claim that this evaluation will allow a clearer definition of possible areas of action and the development of tailored community interventions in mental health.

\section{Methods}

\section{Design and context}

The authors carried out a retrospective, observational and analytical study, regarding all patients seen by a psychiatrist at CHPL in the year 2017 and living in Lisbon ( $N=5161$ ). Data were collected regarding main psychiatric diagnosis (according to the International Classification of Diseases, $10^{\text {th }}$ edition-ICD-10), patients' need for psychiatric hospitalization that year, and whether that admission was voluntary or not.

Then, based on the 2011's national public census data, spatial autocorrelation analysis was performed, regarding the existence of possible geographic clusters, considering general number of patients, main diagnosis, need for psychiatric hospitalization and need for compulsive hospitalization (versus voluntary).

The authors also identified the public primary care facilities $(P C F, N=15)$ in the central area of Lisbon, analyzing the number of patients seen in Psychiatry within multiple radius of distance from each PCF, and how many of them had an admission at an acute psychiatric ward (also within a certain distance radius). It is considered that public PCFs are the main focus of the general treatment of all patients, in coordination with all other medical specialties. Therefore, PCFs can be important focal points for the development of initiatives regarding disease prevention, psychoeducation and patient management.

\section{Participants of the study}

Patients seen in Psychiatry at CHPL in 2017 (aged 18 or older), living in the central and eastern regions of Lisbon (according to the Census 2011 data), both in outpatient and inpatient care. In Portugal, the admission into an acute psychiatric ward is considered a last resort to the treatment of patients, therefore it is a measurement of severity of their disorder. Finally, the compulsory admission at an acute psychiatric ward is determined by the court of law, designated for someone who, due to the psychiatric disorders, creates a dangerous situation for legal assets of a significant value, whether personal or external, of a personal or patrimonial nature, and 
refuses to submit to the necessary medical treatment; and/or does not present the necessary insight to assess the meaning and scope of the consent, when the absence of treatment will severely deteriorate his condition [20].

Individuals without psychiatric diagnosis, or those whose registration did not allow a proper data collection and subsequent statistical analysis were excluded from the study.

\section{Data collection}

Prior to data collection, the study was submitted to and approved by the hospital's ethics and scientific-pedagogical committees (Hospital deliberations: CCP 02/2019 e CES 02/2019), with particular attention paid to the current General Regulation on Data Protection [21].

The collection of the psychiatric follow-up variables (diagnosis, psychiatric admission in 2017, and compulsory admissions that year) was performed through a direct request of the anonym data to the competent entities of the Hospital, thus avoiding patients' identification by the authors.

Regarding geographical data, only one of the main authors had access to the patients' postal code (and only to this information), in order to identify the sub-section of Lisbon (according to the 2011's census) [17], where they reside. The identification of the census subsection (not the specific address, but the lowest denominator of the census data, which includes a number of buildings located in a small area) allowed patients' anonymity to be maintained.

Finally, all PCFs located in central Lisbon were identified and georeferenced, thus allowing a subsequent analysis regarding the accessibility of patients to primary care.

\section{Measures}

Regarding main diagnosis, the patients were grouped into the main categories listed below (increasing the statistical power of the statistical analysis performed):

- Organic, including symptomatic, mental disorders (F00-09);

- Mental and behavioral disorders due to use of alcohol (F10);

- Mental and behavioral disorders due to psychoactive substance use, excluding alcohol (F11-19);

- Schizophrenia, schizotypal and delusional disorders (F20-29);

- Manic Episode and Bipolar Disorder (F30-31);

- Depressive episode, recurrent depressive disorder and persistent mood disorders (F32-34);

- Anxiety disorders (F40-41);

- Obsessive-compulsive disorder (F42);

- Reaction to severe stress, and adjustment disorders (F43);

- Dissociative [conversion], Somatoform and Other neurotic disorders (F44-49);

- Eating Disorders (F50);

- Sexual dysfunction, not caused by organic disorder or disease and Gender identity disorders (F52 + F64);

- Disorders of adult personality and behavior (F60-69);

- Mental retardation (F70-79);

- Disorders of psychological development (F80-90);

- Hyperkinetic Disorders (F90);

- Behavioral and emotional disorders with onset usually occurring in childhood and adolescence, (excluding Hyperkinetic disorders) (F91-98);

- Diseases of the nervous system (G00-99).

All patient variables were measured as categorical ones (admissions in 2017, as well as if it was voluntary or compulsory, were measured as yes/no questions). The exact number of patients living around each PCF was considered (continuous variable). 
Statistical analysis was carried out using the statistical software R studio@, version 3.4.2, as well as QGIS, version 3.0.2, software applications.

Patients were initially spatially merged according to Census 2011 data, at the census subsection tract. Spatial autocorrelation was measured using joint counting statistics, based on the number of existing pairs of adjacent patient/patient locations (queen criterion of contiguity, which includes all units that share a common vertex with each square), and considering $25 \times 25$ meters to represent the area of each patient (average area of the Census' subsections in the area of the city here considered). Statistical analyzes were performed for the overall number of patients, main group of disorders, need for acute psychiatric admission, and whether that admission was voluntary or not, considering $95 \%$ confidence intervals.

Distance between each patient and each PCF was initially estimated (average of 656 meters), as well as distance to CHPL (using "distances" and "multipoint.vars" functions and packages in RStudio). Average distance to the PCF and to CHPL were compared among patients with a psychiatric admission in 2017 versus patients without admissions in that year, and between compulsory admissions versus voluntary ones (using Student's t-test). Then, to access proximity and concentration of patients to PCF, the number of patients living within a defined radius was calculated for each PCF - two different radiuses were calculated: 656 and $1000 \mathrm{~m}$, the latter considering that it was the distance needed to include $75 \%$ of the total number of patients. Comparative analysis of the data collected, identifying the PCF that had the smallest average distance from the patients' residency, and the ones that have the biggest number of patients in each radius, was performed. Statistical analyzes were performed for the overall number of patients, main group of disorders, need for acute psychiatric admission, and compulsory admissions. Considering that the present study had a focus on patients' accessibility to PCF, as they present possible places for development of measures regarding disease prevention and psychoeducation, and also considering that many psychiatric patients have worsened access to PCF (not having an assigned general practitioner), it was accepted that many patients were considered twice, in case their place of residency was associated with more than one PCF.

\section{Results}

In 2017,5161 patients were treated (1.97\% of the corresponding population of the city), with 509 of these patients (9.86\%) being admitted to the acute psychiatric ward. Finally, $35.56 \%$ of these admissions were compulsory (181 patients). As shown in table 1 , Depressive disorders are the most frequent diagnoses in this population, while Schizophrenia, schizotypal and delusional disorders are the most frequent concerning admissions (voluntary and compulsory). Bipolar disorders represent the third most frequent disorder diagnosed.

Table 2 shows the p-values for the joint count statistics performed, not only for each set of disorders (statistical significance was found in Schizophrenia, schizotypal and delusional disorders and so in depressive and persistent mood disorders, with anxiety disorders also showing a p-value of 0.01755 ), but also for the total number of patients, total number of admissions and compulsory admissions, with the overall number of patients reaching statistical significance.

For the overall number of patients, the average distance to the closest PCF is $0.6564 \mathrm{~km}$, and the average distance to CHPL is $3.6867 \mathrm{~km}$. Table 3 compares these average distances between patients with and without admissions in 2017, as well as compulsory admissions versus voluntary ones. Statistical significance was found in both groups, when comparing average distances to the hospital and not to the closest PCF.

Finally, the number of patients living in both 656- and 1000-meter radius, sorted by each PCF, is listed on tables 4 (sorted by total patients, total admissions and compulsory admissions) and 5 (sorted by group of diagnoses).

\section{Discussion}

\section{Do patients live randomly around the city?}

Join count statistics allowed the identification of clusters of patients throughout the city, regarding the overall number of patients and some psychiatric diagnosis. The majority of patients that had contact with the hospital in 2017 does not live randomly in the 
city and there are areas with a higher density of patients ( $p$-value of 0.0001$)$. The same conclusion can be drawn regarding some specific diagnosis, such as depressive disorders, as well as the ones in the schizophrenia spectrum.

Statistical significance was not observed in what could be considered patients with a more severe disorder-namely patients with admissions at the acute psychiatric ward. While there are areas with a higher density of psychiatric patients, it does not seem to lead to the existence of specific locations that could be considered as focal points to more severe cases ( $p$-value of 0.1605 for overall admissions and 0.5705 for compulsory ones).

Do patients with more severe diagnosis live closer to healthcare facilities?

In Portugal primary care facilities are considered the first access to healthcare for every citizen. Therefore, it is expected that the average distance to PCF is smaller than to the hospital, being the general practitioners the first physicians to have contact with these patients.

Patients with a psychiatric admission in 2017 do not seem to live farther away from PCF, compared to the ones without any admission, suggesting that geographical distance and access to healthcare do not seem to be factors related to disease severity.

However, the same does not apply to the hospital. Patients with at least one admission in 2017 live farther away from it ( $p$-value: 0.002 ) and the same applies to the compulsory admitted patients compared to the voluntary ones ( $p$-value: 0.004 ). It can be considered that, for this population, distance and geographical access to the psychiatric hospital may have a role regarding mental health care and treatment.

Are there PCFs with higher prevalence of psychiatric patients?

Considering a 1000m radius, there are two PCFs with more than 1000 patients (USF Penha de França and USF Sétima Colina), followed by two others with more than 800 patients (USF Baixa and USF Fonte Luminosa / UCSP Alameda). These PCFs are also consistently the ones with the higher number of patients, when considering each and every group of diagnoses.

The authors are aware that the identification of buffers of patients, on a certain radius from each PCF, allows each patient to be part of multiple buffers. Since this study is focused on access to health and community care, it is acceptable for some patients to be counted more than once.

The identification of the PCF with a higher number of patients can help the further development of tailored measures, namely public health initiatives and psychoeducative programs. If there are PCFs with more patients, especially for certain disorders, not only they can become the focus for specific strategies, but also a target for better support for general practitioners.

Promoting specific training to general practitioners is a crucial step in every community program. A better knowledge of the environments' characteristics, such as recognition of the patients' "hotspots" and PCF nearby may allow the restructuring of training contents and interventions accordingly.

\section{Advantages, limitations, and recommendations:}

The project becomes relevant for:

- studying the geographical organization of psychiatric patients, as well as possible social determinants of the community in which the patient is inserted, and the access to primary, secondary and tertiary health care;

- allowing future improvement of clinical approaches to the psychiatric patient: promotion of local strategies to prevent mental illness and identification of possible places of risk.

Future research will focus on ecological data associated (at the census level) with possible social-economic factors that can be linked to patients with mental disorders.

The authors advocate further development of local strategies with the aid of information disclosed by the present research, and posterior evaluation of their impact. 


\section{Conclusions}

Our research suggests that, in this area of Lisbon, patients who contact the hospital seem to present some degree of clustering in terms of their residency, both in general and in specific diagnosis. These findings may help the identification of possible "hotspots" of patients, allowing the development of specific community programs (directed to the patients, but also to general practitioners) and the discussion of realistic health policies. The promotion of cost-effective initiatives could also prevent readmissions and increase the general quality of life of psychiatric patients.

\section{Declarations}

CHPL: Centro Hospitalar Psiquiátrico de Lisboa

ICD-10: International Classification of Diseases, $10^{\text {th }}$ edition

PCF: Primary Care Facility

SNS-Serviço Nacional de Saúde

Ethics approval and consent to participate: this project was approved be the CHPL's ethics and scientific-pedagogical committees (Hospital deliberations: CCP 02/2019 e CES 02/2019), following the rules defined in the General Regulation of Data Protection.

Consent for publication: not applicable

Availability of data and materials: not applicable

Competing interests: the first author has presented on the behalf of Tecnifar pharmaceutical, regarding topics not related to the ones discussed in this study.

Funding: No funding was obtained for this study.

Authors' contributions: $\mathrm{MN}$ and $\mathrm{BL}$ were the main authors regarding the design of the study, data demand and discussion. MN was also responsible for the main design of the RStudio code. IC, JA, ML, MS, CP, IC, FG, SG, SN, GP VN and PC participated in the data treatment, statistics and discussion of results. AN was the supervisor of the study, participating in the discussion of results.

All Authors read and approved the manuscript.

Acknowledgements: the authors would like to thank CHPL for providing data for the study in an anonymous form, allowing the development of the project, and Elisabeth Nunes Pereira, who helped with the language revision.

\section{References}

1- World Health Organization and Calouste Gulbenkian Foundation (2014) Social determinants of mental health. Geneva, World Health Organization

2- $\quad$ Direcção-Geral da Saúde (2004) Rede de Referenciação de Psiquiatria e Saúde Mental. Lisbon, Direcção-Geral da Saúde, ISBN: 972-675-089-X

3- $\quad$ Shim R, Koplan C, Langheeim FJP, et al (2014) The Social Determinants of Mental Health: An Overview and Call to Action. Psychiatric Annals. 44(1):22-26, doi.org/10.3928/00485713-20140108-04

4- $\quad$ Santana P (2015) Território e Saúde Mental em Tempos de Crise. Imprensa da Universidade de Coimbra, Portugal, ISBN:978989-26-1105-1, dx.doi.org/10.14195/978-989-26-1105-1 
5- $\quad$ Graif C, Arcaya MC, Diez Roux A V. (2016) Moving to opportunity and mental health: Exploring the spatial context of neighborhood effects. Soc Sci Med 162:50-8 10.1016/j.socscimed.2016.05.036.

6- $\quad$ Chaix B, Leyland AH, Sabel CE, Chauvin P, Råstam L, Kristersson H, et al (2006) Spatial clustering of mental disorders and associated characteristics of the neighbourhood context in Malmö, Sweden, in 2001. J Epidemiol Community Health 60:427-35, 10.1136/jech.2005.040360.

7- $\quad$ Salinas-Pérez JA, García-Alonso CR, Molina-Parrilla C, Jordà-Sampietro E, Salvador-Carulla L. (2012) Identification and location of hot and cold spots of treated prevalence of depression in Catalonia (Spain). Int J Health Geogr 11:1-10, 10.1186/1476072X-11-36.

8- $\quad$ Crump C, Sundquist K, Winkleby MA, Sundquist J. (2013) Comorbidities and mortality in bipolar disorder: a Swedish national cohort study. JAMA Psychiatry 70:931-9, 10.1001/jamapsychiatry.2013.1394.

9- $\quad$ Eastwood JG, Jalaludin BB, Kemp LA, Phung HN. (2014) Bayesian hierarchical spatial regression of maternal depressive symptoms in South Western Sydney, Australia. Springerplus 3:1-10, 10.1186/2193-1801-3-55.

10- Weich S, Blanchard M, Prince M, Burton E, Erens B, Sproston K. (2002) Mental health and the built environment: crosssectional survey of individual and contextual risk factors for depression. Br J Psychiatry 180:428-33, 10.1192/bjp.180.5.428.

11- Fone DL, Lloyd K, Dunstan FD. (2007) Measuring the neighbourhood using UK benefits data: A multilevel analysis of mental health status. BMC Public Health 7:1-13, 10.1186/1471-2458-7-69.

12- Stefansson H, Ophoff RA, Steinberg S, Andreassen OA, Cichon S, Rujescu D, et al. (2009) Common variants conferring risk of schizophrenia. Nature 460:744-7, 10.1038/nature08186.

13- $\quad$ Das-Munshi J, Bécares L, Boydell JE, Dewey ME, Morgan C, Stansfeld SA, et al. (2012) Ethnic density as a buffer for psychotic experiences: Findings from a national survey (EMPIRIC). Br J Psychiatry 201:282-90, 10.1192/bjp.bp.111.102376

14- $\quad$ Moscone F, Knapp M (2005) Exploring the Spatial Pattern of Mental Health Expenditure. J Ment Health Policy Econ 8:205-217

15- Stockdale SE, Wells KB, et al. (2007) The Importance of Social Context: Neighborhood Stressors, Stress-Buffering Mechanisms, and Alcohol, Drug, and Mental Health Disorders. Soc Sci Med. November; 65(9): 1867-1881.

16- Kirby RS, Delmelle E, Eberth JM, (2007) Advances in spatial epidemiology and geographic information systems, Annals of Epidemiology 10.1016/j.annepidem.2016.12.001.

17- Instituto Nacional de Estatística. (2013) Censos 2011 - Preparação, Metodologia e Conceitos. Instituto Nacional de Estatística, I.P, Lisbon, ISBN 978-989-25-0222-9

18- Direção-Geral da Saúde (2017) Programa Nacional para a Saúde Mental 2017. Direção-Geral da Saúde, Lisbon, ISSN: 21841217

19- Xavier M, Paixão I, Mateus P, et al (2017) Relatório da Avaliação do Plano Nacional de Saúde Mental 2007-2016 e propostas prioritárias para a extensão a 2020. Ministério da Saúde, Portugal, https://www.sns.gov.pt/wpcontent/uploads/2017/08/RelAvPNSM2017.pdf . Accessed 01/07/2019

20- $\quad$ Ministério da Saúde (1998) Lei n. ${ }^{\circ}$ 36/98, de 24 de julho - Lei de Saúde Mental. Diário da república - I Série-A n. 169-24-71998, Portugal, www.pgdlisboa.pt/leis/lei_mostra_articulado.php?nid=276\&tabela=leis\&ficha=1\&pagina=1 Accessed 01/07/2019

21- Parlamento Europeu (2016), Regulamento (UE) 2016/679 do parlamento europeu e do conselho de 27 de abril de 2016 relativo à proteção das pessoas singulares no que diz respeito ao tratamento de dados pessoais e à livre circulação desses dados e que revoga a Diretiva 95/46/CE (Regulamento Geral sobre a Proteção de Dados) Jornal Oficial da União Europeia - edição em língua portuguesa, L119: 1-88. 


\section{Tables}

- Tables

\begin{tabular}{|c|c|c|c|}
\hline Group of diagnoses & $\mathrm{N}$ & Total acute admissions in 2017 & Compulsory acute admissions in 2017 (\%total admissions) \\
\hline F00-09 & 290 & 33 & $10(30.3 \%)$ \\
\hline F10 & 307 & 69 & $4(5.8 \%)$ \\
\hline F11-19 & 93 & 34 & $13(38.2 \%)$ \\
\hline F20-29 & 777 & 107 & $54(50.5 \%)$ \\
\hline F30-31 & 486 & 88 & $48(54.5 \%)$ \\
\hline F32-34 & 1460 & 66 & $11(16.7 \%)$ \\
\hline F40-41 & 426 & 1 & $0(0 \%)$ \\
\hline F42 & 87 & 2 & $1(50 \%)$ \\
\hline F43 & 189 & 7 & $0(0 \%)$ \\
\hline F44-49 & 59 & 3 & $3(100 \%)$ \\
\hline F50 & 38 & 2 & $0(0 \%)$ \\
\hline F52 + F64 & 57 & 0 & $0(0 \%)$ \\
\hline F60-69 & 178 & 12 & $3(25 \%)$ \\
\hline F70-79 & 220 & 19 & $6(31.6 \%)$ \\
\hline F80-90 & 8 & 0 & $0(0 \%)$ \\
\hline F90 & 21 & 0 & $0(0 \%)$ \\
\hline F91-98 & 11 & 3 & $0(0 \%)$ \\
\hline G00-99 & 36 & 1 & $1(100 \%)$ \\
\hline No definite diagnosis & 159 & 2 & $2(100 \%)$ \\
\hline Total & 5161 & 509 & 181 (35.6\%) \\
\hline
\end{tabular}

Table 1: number of patients seen in Psychiatry, and respective acute admissions and compulsory ones - total and by group of diagnosis 


\begin{tabular}{|l|l|}
\hline Group of diagnoses & Join count statistics p-value \\
\hline F00-09 & 0.6455 \\
\hline F10 & 0.168 \\
\hline F11-19 & 0.5125 \\
\hline F20-29 & 0.007 \\
\hline F30-31 & 0.785 \\
\hline F32-34 & 0.0002 \\
\hline F40-41 & 0.01755 \\
\hline F42 & 0.511 \\
\hline F43 & 0.563 \\
\hline F44-49 & 0.504 \\
\hline F50 & 0.5015 \\
\hline F52 + F64 & 0.5075 \\
\hline F60-69 & 0.562 \\
\hline F70-79 & 0.0815 \\
\hline F80-90 & 0.4995 \\
\hline F90 & 0.501 \\
\hline F91-98 & 0.500 \\
\hline G00-99 & 0.5035 \\
\hline & \\
\hline Total patients & 0.0001 \\
\hline Total admissions & 0.1605 \\
\hline Compulsory admissions & 0.5705 \\
\hline
\end{tabular}

Table 2: join count statistics p-value regarding all patients followed in 2017

\begin{tabular}{|l|l|l|l|}
\hline \multicolumn{2}{|c|}{} & \multicolumn{2}{|l|}{ Average distance $(\mathrm{km})$} \\
\cline { 3 - 4 } & Closest PCF & CHPL \\
\hline \multirow{3}{*}{ Acute admissions in 2017} & Yes & 0.6569 & 3.8137 \\
\cline { 2 - 4 } & No & 0.6564 & 3.6725 \\
\cline { 2 - 4 } & p-value & 0.822 & $\mathbf{0 . 0 0 2}$ \\
\hline \multirow{3}{*}{ Type of admissions in 2017 } & Compulsory & 0.6576 & 3.9851 \\
\cline { 2 - 4 } & Voluntary & 0.6564 & 3.7216 \\
\cline { 2 - 4 } & p-value & 0.795 & $\mathbf{0 . 0 0 4}$ \\
\hline
\end{tabular}

Table 3: average distances to the closest PCF and CHPL 


\begin{tabular}{|l|l|l|l|l|l|l|l|}
\hline \multirow{2}{*}{} & \multicolumn{2}{l|l}{ Total Patients } & \multicolumn{2}{l|}{ Total Admissions } & \multicolumn{2}{l|}{ Compulsory admissions } \\
\cline { 2 - 8 } & $656 \mathrm{~m}$ & $1000 \mathrm{~m}$ & $656 \mathrm{~m}$ & $1000 \mathrm{~m}$ & \multicolumn{2}{l|}{$656 \mathrm{~m}$} & $1000 \mathrm{~m}$ \\
\hline UCSP Lapa & 157 & 423 & 20 & 45 & 9 & 20 \\
\hline UCSP Marvila & 110 & 283 & 10 & 20 & 4 & 8 \\
\hline UCSP Mónicas & 383 & 697 & 48 & 76 & 21 & 28 \\
\hline UCSP Olivais & 135 & 444 & 11 & 37 & 3 & 8 \\
\hline UCSP Penha de Franca & 581 & 1145 & 68 & 133 & 20 & 51 \\
\hline USF Arco & 201 & 498 & 22 & 57 & 10 & 24 \\
\hline USF Loios & 224 & 523 & 15 & 41 & 3 & 9 \\
\hline USF Monte Pedral & 323 & 716 & 33 & 70 & 7 & 25 \\
\hline USF Oriente & 252 & 516 & 30 & 50 & 5 & 16 \\
\hline USF Ribeira Nova & 284 & 490 & 31 & 58 & 14 & 27 \\
\hline USF Sétima Colina & 552 & 1175 & 60 & 126 & 21 & 51 \\
\hline USF Sofia Abecassis & 214 & 484 & 19 & 45 & 9 & 23 \\
\hline USF. Baixa & 363 & 873 & 47 & 109 & 18 & 37 \\
\hline USF Fonte Luminosa / UCSP Alameda & 421 & 858 & 37 & 72 & 14 & 30 \\
\hline USF Jardins da Encarnacão / USF Vasco Gama & 121 & 430 & 8 & 37 & 1 & 9 \\
\hline Total & 4321 & 9555 & 459 & 976 & 159 & 366 \\
\hline
\end{tabular}

Table 4: number of patients living around each PCF. 


\begin{tabular}{|c|c|c|c|c|c|c|c|c|c|c|c|c|c|c|c|c|c|c|c|c|c|c|c|c|c|c|c|c|c|c|c|c|c|c|c|c|}
\hline & \multicolumn{36}{|c|}{ ICD-10 Classifications } \\
\hline & \multicolumn{2}{|c|}{ F00-09 } & \multicolumn{2}{|c|}{ F10 } & \multicolumn{2}{|c|}{ F11-19 } & \multicolumn{2}{|c|}{ F 20-29 } & \multicolumn{2}{|c|}{ F30-31 } & \multicolumn{2}{|c|}{ F32-34 } & \multicolumn{2}{|c|}{ F40-41 } & \multicolumn{2}{|c|}{ F42 } & \multicolumn{2}{|c|}{ F43 } & \multicolumn{2}{|c|}{ F44-49 } & \multicolumn{2}{|c|}{ F50 } & \multicolumn{2}{|c|}{$F 52+F$} & \multicolumn{2}{|c|}{ F60-69 } & \multicolumn{2}{|c|}{ F70-79 } & \multicolumn{2}{|c|}{ F80-90 } & \multicolumn{2}{|c|}{ F90 } & \multicolumn{2}{|c|}{ F91-98 } & \multicolumn{2}{|c|}{ G00-99 } \\
\hline & & & 656 & 100 & 656 & 1000 & 658 & 1000 & $65 d 1$ & & 6561 & 10006 & $65 d 1$ & & 550 & & & & & 10006 & $65 \mathrm{Cl}_{1}$ & & 56 & & 6561 & & $65 d 1$ & & & & 656 & & & 1000 & d65d1 & 1000 \\
\hline & $\mathrm{m}$ & $\mathrm{m}$ & $\mathrm{m}$ & $\mathrm{m}$ & $\mathrm{m}$ & $\mathrm{m}$ & $\mathrm{m}$ & $\mathrm{m}$ & $\mathrm{m}$ & $\mathrm{m}$ & $\mathrm{m}$ & $\mathrm{m}$ & $\mathrm{m}$ & $\mathrm{m}$ & $\mathrm{m}$ & $\mathrm{m}$ & $\mathrm{m}$ & $\mathrm{m}$ & $\mathrm{m}$ & $\mathrm{m}$ & $\mathrm{m}$ & $\mathrm{m}$ & $\mathrm{m}$ & $\mathrm{m}$ & $\mathrm{m}$ & $\mathrm{m}$ & $\mathrm{m}$ & $\mathrm{m}$ & $\mathrm{m}$ & $\mathrm{m}$ & $\mathrm{m}$ & $\mathrm{m}$ & $\mathrm{m}$ & $\mathrm{m}$ & $\mathrm{m}$ & $\mathrm{m}$ \\
\hline UCSP Lapa & 8 & 23 & 6 & 20 & 4 & 7 & 25 & 64 & 18 & 48 & 38 & 98 & 13 & 37 & 5 & 9 & 6 & 18 & 0 & 7 & 0 & 3 & 0 & 7 & 6 & 13 & 5 & 11 & 0 & 0 & 5 & 5 & 0 & 1 & 1 & 3 \\
\hline $\begin{array}{r}\text { UCSP } \\
\text { Marvila }\end{array}$ & 9 & 20 & 11 & 22 & 0 & 3 & 9 & 31 & 9 & 22 & 34 & 90 & 7 & 20 & 2 & 6 & 4 & 12 & 2 & 4 & 1 & 1 & 2 & 6 & 0 & 6 & 7 & 14 & 0 & 0 & 0 & 1 & 0 & 0 & 1 & 2 \\
\hline $\begin{array}{r}\text { UCSP } \\
\text { Mónicas }\end{array}$ & 25 & 46 & 32 & 50 & 12 & 17 & 56 & 109 & 34 & 55 & 98 & 190 & 38 & 66 & 2 & 5 & 16 & 26 & 4 & 8 & 2 & 4 & 3 & 8 & 18 & 30 & 12 & 24 & 2 & 2 & 0 & 1 & 2 & 3 & 1 & 1 \\
\hline $\begin{array}{r}\text { UCSP } \\
\text { Olivais }\end{array}$ & 12 & 29 & 8 & 17 & 3 & 4 & 18 & 61 & 11 & 44 & 46 & 130 & 9 & 41 & 1 & 10 & 2 & 14 & 2 & 5 & 0 & 1 & 1 & 1 & 0 & 19 & 7 & 25 & 0 & 2 & 1 & 2 & 0 & 2 & 0 & 5 \\
\hline $\begin{array}{r}\text { UCSP } \\
\text { Penha de } \\
\text { Franca }\end{array}$ & 33 & 66 & 32 & 75 & 13 & 25 & 122 & 217 & 41 & 94 & 151 & 299 & 43 & 89 & 9 & 15 & 15 & 37 & 8 & 9 & 9 & 12 & 7 & 14 & 27 & 38 & 18 & 32 & 1 & 2 & 1 & 3 & 1 & 3 & 2 & 5 \\
\hline USF Arco & 11 & 35 & 10 & 26 & 2 & 9 & 28 & 75 & 29 & 58 & 42 & 113 & 15 & 43 & 4 & 11 & 8 & 16 & 3 & 8 & 3 & 3 & 3 & 9 & 6 & 15 & 13 & 19 & 0 & 0 & 0 & 1 & 1 & 1 & 5 & 7 \\
\hline USF Loios & 9 & 18 & 5 & 19 & 3 & 4 & 34 & 85 & 31 & 60 & 68 & 160 & 20 & 43 & 1 & 9 & 7 & 18 & 1 & 6 & 3 & 6 & 0 & 3 & 9 & 26 & 18 & 32 & 1 & 2 & 0 & 2 & 0 & 2 & 2 & 3 \\
\hline $\begin{array}{r}\text { USF Monte } \\
\text { Pedral } \\
\end{array}$ & 18 & 35 & 22 & 41 & 10 & 23 & 35 & 102 & 25 & 57 & 104 & 217 & 25 & 58 & 4 & 10 & 15 & 30 & 4 & 7 & 1 & 6 & 5 & 10 & 8 & 20 & 12 & 24 & 0 & 2 & 2 & 2 & 1 & 1 & 2 & 4 \\
\hline $\begin{array}{r}\text { USF } \\
\text { Oriente }\end{array}$ & 13 & 25 & 19 & 34 & 10 & 21 & 28 & 72 & 14 & 41 & 79 & 159 & 21 & 40 & 4 & 7 & 11 & 21 & 4 & 7 & 1 & 4 & 5 & 7 & 5 & 14 & 12 & 20 & 0 & 0 & 1 & 2 & 1 & 1 & 2 & 3 \\
\hline $\begin{array}{r}\text { USF } \\
\text { Ribeira } \\
\text { Nova } \\
\end{array}$ & 13 & 28 & 18 & 31 & 4 & 13 & 47 & 74 & 33 & 50 & 64 & 118 & 26 & 44 & 5 & 9 & 6 & 11 & 4 & 7 & 0 & 2 & 5 & 8 & 9 & 15 & 17 & 21 & 0 & 0 & 0 & 1 & 1 & 1 & 5 & 7 \\
\hline $\begin{array}{r}\text { USF Sétima } \\
\text { Colina } \\
\end{array}$ & 38 & 63 & 37 & 73 & 10 & 25 & 113 & 204 & 43 & 99 & 133 & 330 & 44 & 92 & 6 & 15 & 14 & 48 & 7 & 12 & 7 & 12 & 6 & 13 & 26 & 39 & 13 & 32 & 1 & 2 & 1 & 2 & 1 & 3 & 1 & 4 \\
\hline $\begin{array}{l}\text { USF Sofia } \\
\text { Abecassis }\end{array}$ & 12 & 29 & 11 & 26 & 2 & 11 & 35 & 73 & 28 & 53 & 48 & 106 & 15 & 45 & 6 & 11 & 9 & 18 & 5 & 7 & 3 & 4 & 4 & 9 & 4 & 13 & 6 & 19 & 0 & 1 & 1 & 4 & 1 & 1 & 3 & 7 \\
\hline USF Baixa & 25 & 60 & 31 & 59 & 9 & 20 & 60 & 135 & 28 & 72 & 97 & 235 & $30 \mid$ & 75 & 3 & 11 & 12 & 31 & 6 & 9 & 1 & 9 & 6 & 9 & 13 & 43 & 12 & 26 & 0 & 3 & 0 & 2 & 3 & 3 & 0 & 4 \\
\hline $\begin{array}{r}\text { USF Fonte } \\
\text { Luminosa / } \\
\text { UCSP } \\
\text { Alameda } \\
\end{array}$ & 30 & 46 & 27 & 54 & 7 & 13 & 72 & 156 & 48 & 91 & 93 & 224 & 37 & 65 & 7 & 14 & 16 & 36 & 6 & 7 & 5 & 9 & 3 & 7 & 10 & 23 & 13 & 25 & 0 & 0 & 4 & 6 & 0 & 1 & 2 & 2 \\
\hline $\begin{array}{r}\text { USF Jardins } \\
\text { da } \\
\text { Encarnacão } \\
/ \text { USF } \\
\text { Vasco } \\
\text { Gama } \\
\end{array}$ & 8 & 29 & 6 & 17 & 3 & 4 & 20 & 61 & 9 & 39 & 37 & 130 & 13 & 39 & 1 & 7 & 1 & 14 & 1 & 5 & 0 & 2 & 0 & 1 & 2 & 19 & 6 & 24 & 0 & 1 & 1 & 2 & 0 & 2 & 0 & 5 \\
\hline Total & 264 & 552 & 275 & 564 & 92 & 199 & 702 & 1519 & 401 & 883 & $11322^{2}$ & $2599^{3}$ & 356. & 797 & 60 & 149 & 142 & 350 & 57 & 108 & 36 & 78 & 50 & 112 & 143 & 333 & 171 & 348 & 5 & 17 & 17 & 36 & 12 & 25 & 27 & 62 \\
\hline
\end{tabular}

Table 5: number of patients living around each PCF, sorted by group of diagnosis. 